\title{
From the Editor of Sexuality and Disability: The Next Barrier and Opportunity-Moving Together and Away from Tunnel Vision
}

\author{
Sigmund Hough ${ }^{1}$
}

Published online: 4 May 2017

(C) Springer Science+Business Media New York 2017

With barriers, come opportunities. The international field of sexuality and disability has a growing voice. A voice that says "We count, and we need to be considered." Less sitting in silence and whispering in the dark. The age has evolved to now address needs, issues and concerns. One additional future direction is to join others, not just locally and nationally, but internationally. Multi-site research studies can be tremendously effective to increase healthcare awareness, enrich communication, cultivate knowledge, and stimulate meaningful conversations. I look forward to reading the expansion and bridging of professional connections ahead.

The journal of Sexuality and Disability remains a professional home for many, and a place of professional rejuvenation and exploration for still more. If you are new to the journal, we give to you a "BIG WELCOME" to participate as a reader, author, academician, clinician, educator, service provider, researcher, advocate, and individual or individuals seeking information. Over decades of contribution to the literature on sexuality and disability, we have been a part of the growth and understanding. Now most importantly, we continue to be a part of change in how we look and examine the topic, the need, and the response in terms of best practice- evidence based approaches. With the intelligence, experience, motivation and commitment from our authors, readership, peer reviewers and editorial board, and resources with guidance from the Springer Staff, our journal's mission continues to be strong and meaningful.

Sexuality and Disability continues to provide original impact articles addressing the mental health and medical aspects of sexuality in relation to rehabilitation, hospital, academic and community settings, publishing up-to-date articles, case studies, clinical practice reports, reviews, featured articles, historical articles, special grand rounds topics, brief research reports and survey data reports. Value benefit is provided to authors through worldwide electronic exposure and professional access, while readership gains from scholarly contributions to advance the field through research, best-practice and educational

Sigmund Hough

Sigmund_Hough@hms.harvard.edu

1100 Cummings Center, Suite 207, Beverly, MA 01915-6144, USA 
articles. The refined lens of individual contributions from the local and international community continues to deliver a wealth of information on the topic of sexuality and disability for the reader. Thank you for joining our professional community. 